\title{
Uma Linguagem Visual para Avaliação Adaptativa de Aprendizagem baseada em Gramática de Grafos
}

\author{
Priscilla Lanne C. de Leão ${ }^{1}$, Carla A. Lima Reis ${ }^{2}$ \\ ${ }^{1}$ Programa de Pós-Graduação em Engenharia Elétrica (PPGEE), \\ Universidade Federal do Pará (UFPA), \\ Serviço Federal de Processamento de Dados (SERPRO) \\ ${ }^{2}$ Departamento de Informática - Universidade Federal do Pará (UFPA) \\ \{lanne.bel@orm.com.br, clima@ufpa.br\}
}

Resumo. Este artigo propõe um modelo para avaliação adaptativa de aprendizagem que permite a modelagem visual de avaliações. A ferramenta AvaWeb, desenvolvida a partir deste modelo, permite o gerenciamento de questões e a edição gráfica de avaliações, além de fornecer um ambiente de execução de avaliações para o aluno. A especificação da linguagem visual utilizada foi realizada através de Gramática de Grafos.

Palavras-chave: avaliação de aprendizagem, avaliação adaptativa, gramática de grafos.

\section{A Graph Grammar Based Visual Language for Adaptative Learning Assessment}

Abstract. This paper proposes a model for adaptative learning assessment allowing visual modeling of assessments. Avaweb, the tool developed from this model, provides question management, graphical edition for assessments and also an assessment execution environment for the student. The visual language was specified through Graph Grammars.

Keywords: learning assessment; adaptative assessment, graph grammars.

\section{Introdução}

As tecnologias de informação e comunicação existentes têm aperfeiçoado, dentre outras áreas, a área da Educação, e aumentado a motivação para a pesquisa e desenvolvimento de novas soluções. Metodologias e práticas de ensino adaptadas a esta realidade visam melhorar a atuação do professor transformando-o em um orientador, que estando bem preparado e sendo auxiliado por ferramentas eficazes, pode propiciar ao aluno diversos caminhos para atingir o conhecimento.

A avaliação de aprendizagem tem papel fundamental no processo de ensinoaprendizagem, pois através da avaliação se obtém o termômetro de como o trabalho do professor está sendo conduzido e de como o aluno está assimilando o conhecimento proposto. A avaliação não tem apenas o caráter de medir e julgar, mas também traz indicativos de pontos de melhorias, tanto para o professor quanto para o aluno, buscando reflexão para perguntas como: Será que os objetivos pretendidos estão sendo alcançados? Os alunos estão acompanhando o processo de aprendizagem? Quais pontos precisam ser revisados ou explorados de outra maneira para se adaptar às peculiaridades de cada aluno?

O uso de ferramentas computacionais para avaliação pode auxiliar não somente o professor, mas também o aluno, que nesta abordagem tem o papel central (Cerny, 2001), conduzindo o seu aprendizado, fazendo uso de técnicas e ferramentas, definidas e oferecidas pelo professor orientador, que passa a ter o papel de orientador/mediador intelectual, emocional, gerencial, comunicacional e ético (Muran, 2001).

Um dos principais problemas que um professor enfrenta está na falta de ferramentas adequadas para definição e gerenciamento de suas avaliações (provas, exercícios, trabalhos, etc.). Há carência de ferramentas que permitam ao professor 
acompanhar suas avaliações, definir a sequência das suas questões, definir quando uma avaliação deve ser personalizada para determinados alunos (avaliação adaptativa) e obter relatórios com informações que permitam direcionar a melhoria do ensino.

Partindo da necessidade de prover mais funcionalidades nas ferramentas de avaliação e, ao mesmo tempo, facilitar o trabalho do professor, buscou-se uma solução que envolvesse o uso de linguagem visual para definição de avaliação adaptativa e a aplicação automática de avaliações definidas pelo professor para os alunos, escondendo destes usuários a complexidade inerente à coordenação desta tarefa.

Este artigo propõe um modelo conceitual de avaliação adaptativa de aprendizagem, com características diferenciadas em relação a ferramentas similares. Foi utilizada a abordagem de Gramática de Grafos para especificar e modelar a linguagem visual de avaliações (implementada através de um editor gráfico), assim como especificar a semântica (execução) de uma avaliação adaptativa neste modelo. $\mathrm{O}$ uso desta abordagem visa aumentar a aceitação da ferramenta, chamada AvaWeb, através de sua facilidade de uso para o professor e de entendimento dos conceitos inerentes a uma avaliação, gerando uma documentação precisa e completa do modelo que se deseja construir e facilitando também o desenvolvimento de protótipos.

$\mathrm{O}$ artigo está organizado de modo a apresentar o modelo conceitual e também a ferramenta desenvolvida. Na seção 2 será mostrado o modelo de avaliação de aprendizagem proposto neste trabalho juntamente com alguns exemplos do protótipo da ferramenta AvaWeb. Na seção seguinte será descrito o editor gráfico de avaliação AvaEditor. A linguagem visual desenvolvida para construção do protótipo será descrita na seção 4. Serão apresentados alguns trabalhos relacionados na seção 5 . Na seção 6 serão colocadas algumas considerações finais e por fim, na última seção, serão listadas as referências bibliográficas.

\section{Modelo de Avaliação de Aprendizagem}

O modelo proposto para avaliação adaptativa de aprendizagem é baseado na necessidade de existência de testes e provas ao longo do processo de avaliação de aprendizagem. A preocupação deste modelo, além de prover um ambiente para cadastro de questões e o ambiente de execução de avaliações para os alunos, é dotar o professor de uma ferramenta em que ele possa elaborar suas avaliações através de um editor gráfico que permite distribuir visualmente as questões que compõem as avaliações e possa em cada avaliação desenvolver de forma criativa a montagem de uma prova ou exercício, balanceando as questões aplicadas de acordo com o resultado esperado pelo aluno (acerto ou erro) através de um sequienciamento de questões e gerando avaliações individualizadas para os alunos.

O professor dispõe durante a elaboração da avaliação de dois conceitos para cada questão: Questão Específica - o professor define explicitamente qual a questão desejada a partir das questões que estão disponíveis no banco de questões e a Questão

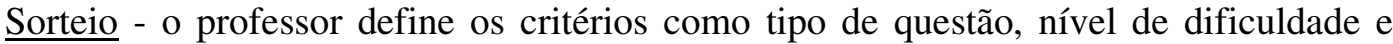
assunto para a questão desejada. Quando a avaliação for aplicada a uma turma, para cada aluno será sorteada uma questão disponível no banco de questões que atenda aos critérios definidos.

Além destes elementos, o editor gráfico de avaliações fornece ao professor símbolos que representam a ligação entre cada questão. Esta ligação pode ser uma conexão acerto, conexão erro ou uma conexão indiferente. Tais conexões são usadas entre questões e representam o resultado do aluno sobre a questão que ele esteja respondendo. De acordo com este resultado, se ele acertar, errar ou independentemente do resultado (acertar ou errar) servem de orientação para a próxima questão a ser respondida pelo aluno. 


\section{1 -Visão Geral da Arquitetura AvaWeb}

Uma visão geral da arquitetura da ferramenta $A v a W e b$ é a apresentada na figura 1.

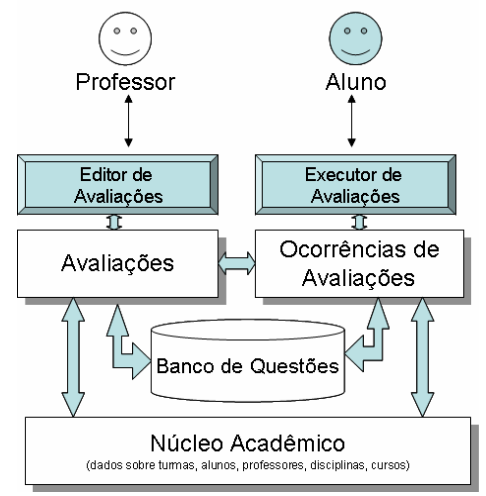

Figura 1 - Visão Geral do Modelo AvaWeb

O aluno interage com Executor de Avaliações (do pacote Avaliador) que coordena a execução das avaliações e registra seus resultados. O professor, por sua vez, interage com o Editor Gráfico de Avaliações AvaEditor, que permite manipular avaliações e questões do Banco de questões. Na manipulação de Avaliações, o professor utiliza um editor gráfico que permite a modelagem visual da avaliação e a sua associação a turmas ou grupos de alunos.

\section{2 - Principais Componentes}

Para atender aos requisitos de avaliação adaptativa foram propostos quatro componentes principais, descritos a seguir:

- Banco de Questões: Possui questões, que são relacionadas a assuntos e podem ser de vários tipos (verdadeiro/falso, múltipla escolha, discursiva e trabalho). As questões podem apresentar níveis de dificuldades diferentes, além de restrições de acesso por professor, disciplina ou curso. Cabe ressaltar que o uso do banco de questões propicia o compartilhamento de questões com outros professores, permitindo a troca de informações e experiências entre os docentes. As telas mostradas na figura 2 ilustram o cadastro de questões do tipo Discursiva e do tipo Trabalho.
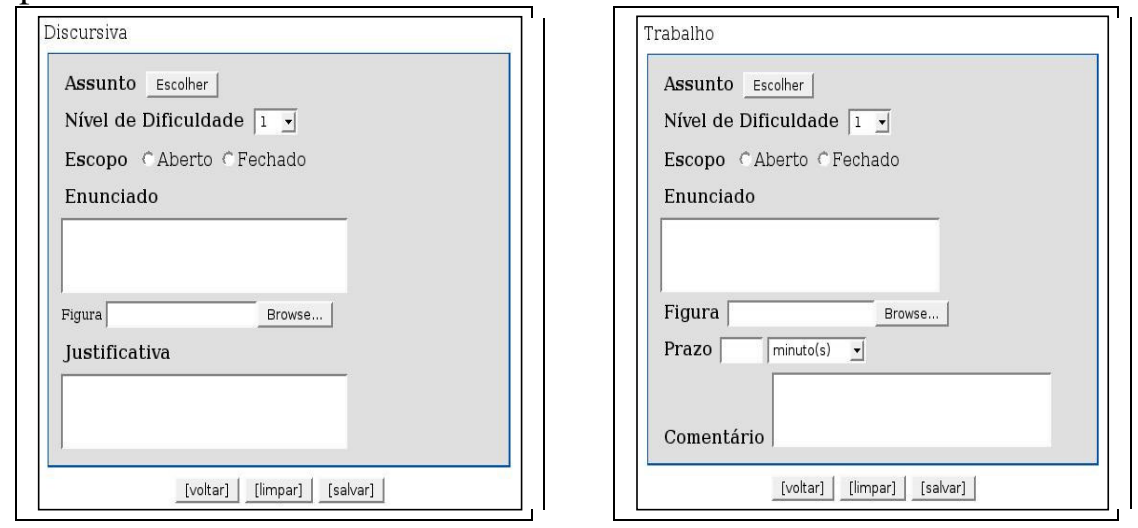

Figura 2 - Cadastro de Questão

Em todos os tipos de questões é disponibilizado um campo para que o professor insira uma figura. O campo Escopo define se a questão estará disponível para todos os tipos de avaliação. $\mathrm{O}$ escopo Aberto indica que poderá ser usada em 
qualquer tipo de avaliação, enquanto que escopo Fechado, a questão só poderá ser usada em avaliação do tipo Prova ou Desafio. Na questão do tipo Discursiva, o professor poderá cadastrar no campo Justificativa informações gerais sobre a resposta esperada para a questão. Na questão do tipo Trabalho é possível definir o tempo que ele terá para ser realizado, o campo Prazo é o que permite informar este tempo através do valor e a unidade de tempo que a questão tem para ser feita.

- Avaliação da Aprendizagem: Este componente inclui a linguagem visual de avaliação (editor gráfico). Avaliações referenciam questões do banco de questões e indicam o caminho a ser percorrido pelo aluno dependendo dos resultados (acertou, errou ou indiferente) para cada questão, podendo ainda incluir questões a serem sorteadas no momento da avaliação.

- Dados do Sistema Acadêmico (Núcleo Acadêmico): Este componente apóia a execução dos demais citados, pois possui informações sobre alunos, professores, turmas, disciplinas e ainda informações de segurança do sistema.

- Aplicação da Avaliação: Este componente aplica avaliações aos alunos através de telas e formulários em páginas web. Para a aplicação são sorteadas questões (quando o professor assim definir), além de registrar as respostas fornecidas, permitindo análise posterior dos resultados.

O protótipo AvaWeb está em fase de conclusão. Especificamente os módulos referentes ao Banco de Questões e ao Editor de Avaliação AvaEditor estão sendo validados por um grupo de professores que atualmente ministram disciplinas no curso Bacharelado em Ciência da Computação da UFPA. O ambiente do aluno e o módulo de relatórios que serão emitidos pela ferramenta estão em fase final de implementação.

\section{Definição Visual de uma Avaliação de Aprendizagem}

O Editor de Avaliações - AvaEditor faz parte do AvaWeb e é utilizado pelo professor para elaboração de avaliações adaptativas. A seqüência de telas da figura 3 mostra um exemplo de avaliação definida pelo AvaEditor. Inicialmente o editor mostra (Figura 3a) uma avaliação vazia apenas com os marcadores de início e fim (Nodos INICIO e FIM). Ao criar uma nova avaliação, o professor poderá informar (Figura 3b) a descrição, objetivos, nota, peso e duração da avaliação.

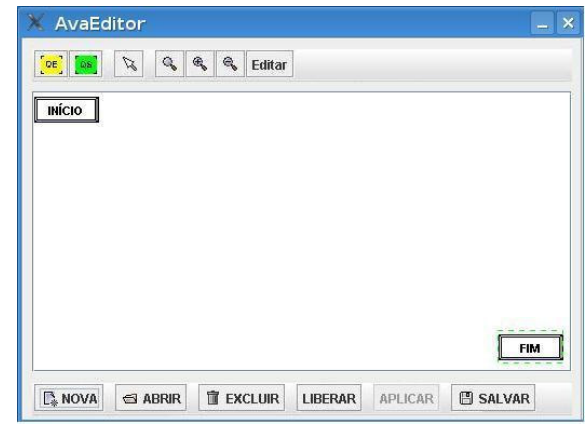

Figura 3a - Tela Inicial do AvaEditor

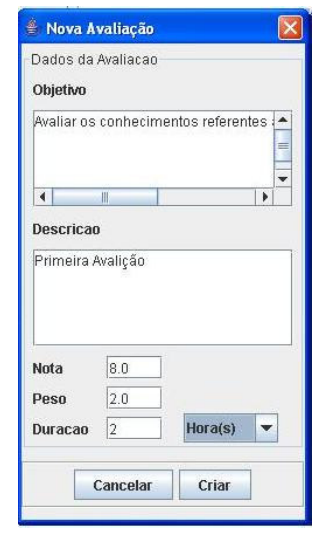

Figura 3b - Cadastro de Avaliação

Na figura 4a, o símbolo QE indica Questão Específica e o símbolo QS representa a Questão Sorteio. A sequiência de execução das questões na avaliação é definida através de conexões (o editor valida a inclusão de conexões) do tipo acertou, errou ou indiferente (que representa que o aluno pode acertar ou errar a questão) através de um menu, conforme ilustrado na figura $4 \mathrm{~b}$. 


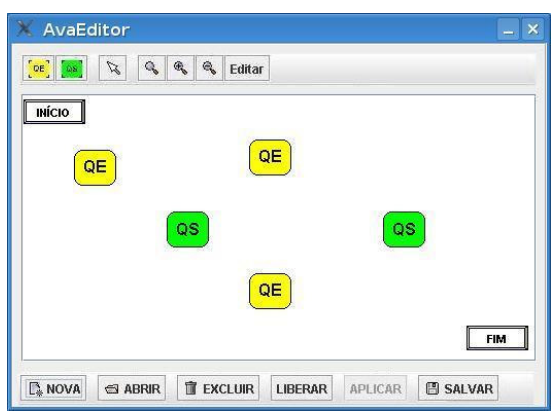

Figura 4a - Disposição das Questões

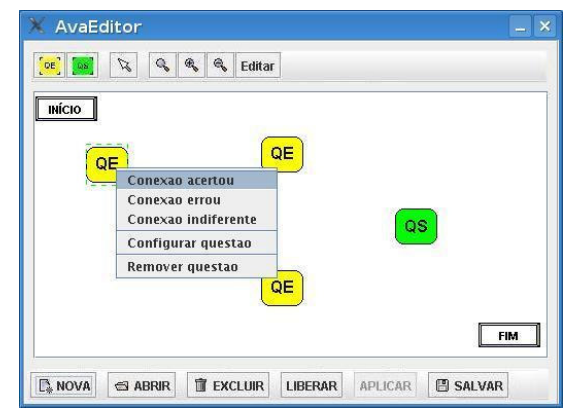

Figura 4b - Conexões entre Questões

O professor utiliza o editor para definir sua avaliação, podendo alterar questões, incluir e remover conexões (conforme mostra a figura 5a). Uma visão de diversas questões distribuídas e suas conexões é ilustrada na figura $5 \mathrm{~b}$.

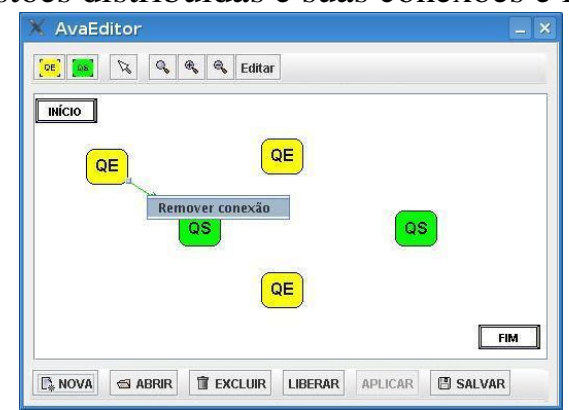

Figura 5a - Opção de Remover conexão

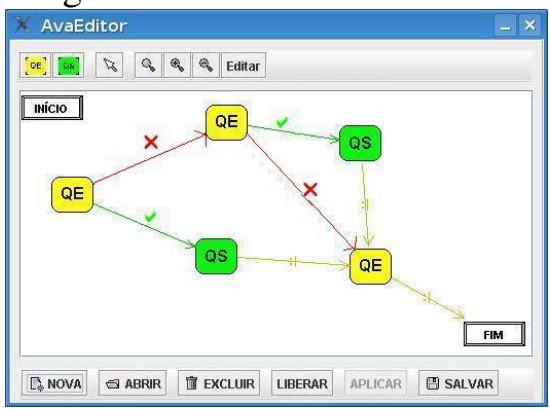

Figura 5b - Visão de Diversas Questões

O nodo FIM pode receber diversas conexões indicando os possíveis caminhos de acordo com o desempenho do aluno. Para cada objeto questão representado na tela, o professor deverá escolher a questão específica (ver figura 6a) ou selecionar os critérios da Questão Sorteio. O professor deve também informar o tipo de questão, assunto e nível de dificuldade desejado (figura 6b) e selecionar a partir da lista que atende aos critérios definidos, qual a questão do banco de questões ele deseja realmente incluir. Em seguida, é possível definir o valor da questão na avaliação (figura 6c).

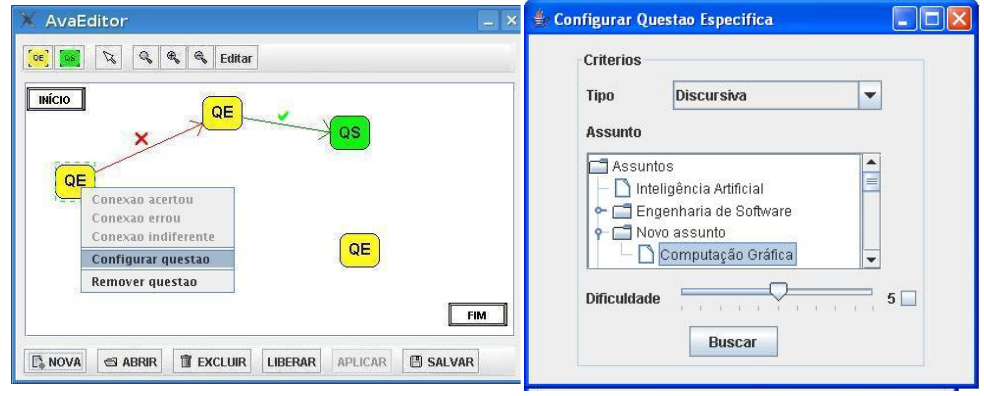

Figura 6a - Opção Configurar Questão
Figura 6b - Configurar Questão Específica

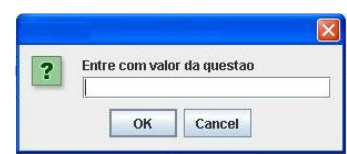

Figura 6c - Definir valor da questão

Quando a avaliação estiver definida, o professor pode solicitar a sua liberação, fazendo com que o editor verifique se tem alguma pendência, como por exemplo, alguma questão que não foi definida ou alguma questão que não está conectada a nenhuma outra ou ao nodo FIM. Após liberação da avaliação, o professor poderá aplicála a turma ou a grupos de alunos. Neste caso, ele deverá selecionar a disciplina e turma desejada, e os alunos que farão a avaliação. As figuras ilustradas em 7a, 7b, 7c e 7d mostram as telas de cada seleção até que a avaliação seja aplicada. 


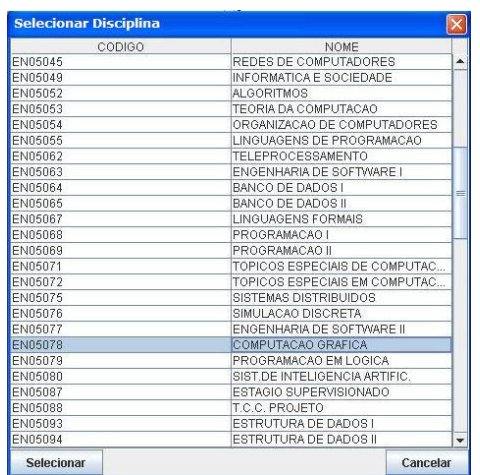

7a - Selecionar Disciplina

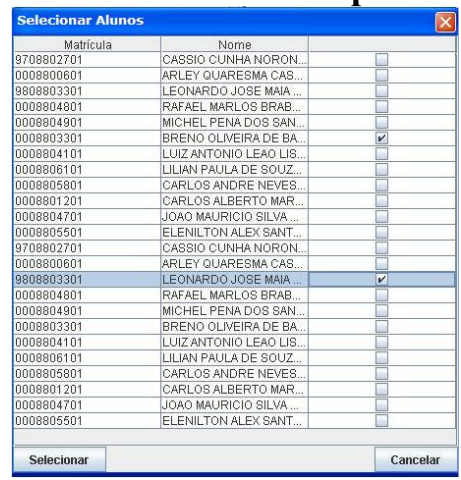

7c- Selecionar Alunos

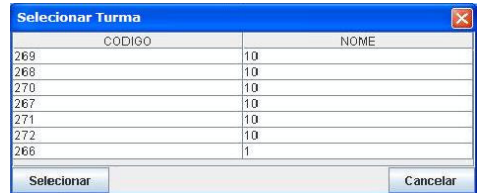

7b - Selecionar a Turma

A partir da aplicação da avaliação, os alunos envolvidos recebem em seu ambiente o aviso da avaliação a ser feita.

\section{Especificação da Linguagem Visual para Definição de Avaliações}

Tanto para o mapeamento dos objetos gráficos na tela quanto para a validação das avaliações criadas foi utilizada a abordagem de Gramática de Grafos (GG). Uma especificação formal descreve de forma clara e não ambígua um sistema através de uma linguagem com sintaxe e semântica bem definidas (Ribeiro, 2000). A escolha desta abordagem se deve aos seguintes fatores:

- GGs possuem natureza intuitiva e têm atraído bastante atenção por permitir modelagem de diversos tipos de aplicações, tais como: sistemas concorrentes, linguagens visuais, reconhecimento e geração de imagens e biologia;

- Por ser um método formal, o uso de GG provê uma especificação sem ambigüidades, permitindo entendimento mais profundo e provas formais;

- A abordagem proposta em Bardohl (1999) citada por Reis (2003) para especificação de linguagens visuais usando GGs pode auxiliar tanto os desenvolvedores da ferramenta (pela especificação rigorosa) quando os seus usuários com relação ao uso de notação adequada para realização de suas tarefas (no caso, elaboração de avaliações).

Uma gramática de grafos especifica um sistema em termos de estados, modelados por grafos, e mudanças de estados, modeladas por derivações. A aplicação de uma regra a um grafo $\mathrm{G}$ é chamada passo de derivação e isso só é possível se existe uma ocorrência do lado esquerdo (L) da regra do grafo atual G. O lado direito (R) da regra define o grafo resultante da aplicação desta regra. A interpretação operacional de uma regra $\mathrm{r}: \mathrm{L} \rightarrow \mathrm{R}$ descreve a base desta abordagem de especificação: Itens em $\mathrm{L}$ que não tem uma imagem em $\mathrm{R}$ são apagados; Itens em $\mathrm{L}$ que são mapeados para $\mathrm{R}$ são mantidos; Itens em R que não tem uma pré-imagem em L são criados. 
O grafo-tipo representa os tipos de nodos e arcos do sistema (símbolos da linguagem podem ser nodos do grafo-tipo). O grafo inicial e os grafos derivados das transformações devem ser compatíveis com o grafo-tipo.

A especificação do sistema $A v a W e b$ foi dividida em duas partes: Sintaxe que descreve o funcionamento do editor de avaliação (utilizado pelo professor) e a semântica que descreve a execução das avaliações geradas pelo editor gráfico (comportamento percebido pelo aluno), conforme serão mostrados nos próximos itens.

\subsection{Sintaxe da Avaliação no AvaWeb}

\subsubsection{Alfabeto}

O alfabeto da linguagem de avaliações é formado pelos símbolos visuais da figura 8.

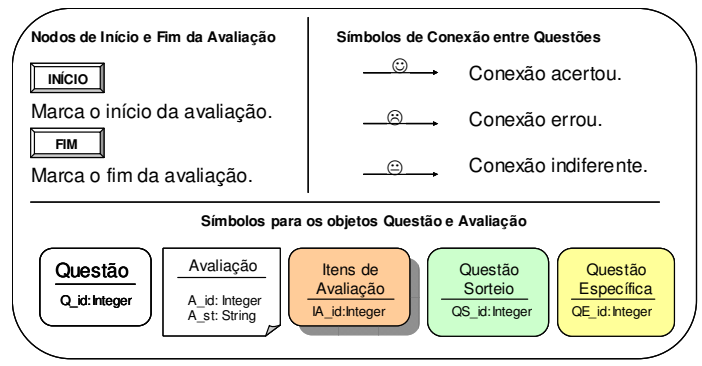

Figura 8 - Símbolos visuais do alfabeto do AvaWeb.

\subsubsection{Regras para a Criação de Avaliações no AvaWeb}

Baseada no alfabeto ilustrado na figura 8 e no grafo-tipo proposto (não apresentado aqui) foram criadas regras que geram avaliações sintaticamente corretas, guiando a edição das mesmas para auxiliar o professor.

A regra InserirQuestãoEspecífica(A_id, q_id), ilustrada na figura 9, tem como objetivo adicionar uma questão na avaliação. No lado esquerdo, observa-se que dada uma avaliação existente com identificador id=A_id, com status "Em elaboração" e que não possui a Questão Especifica Q_id (indicada pelo X sobre os itens do grafo ${ }^{1}$ ), o lado direito resulta na Avaliação A_id referenciando a Questão Especifica Q_id.

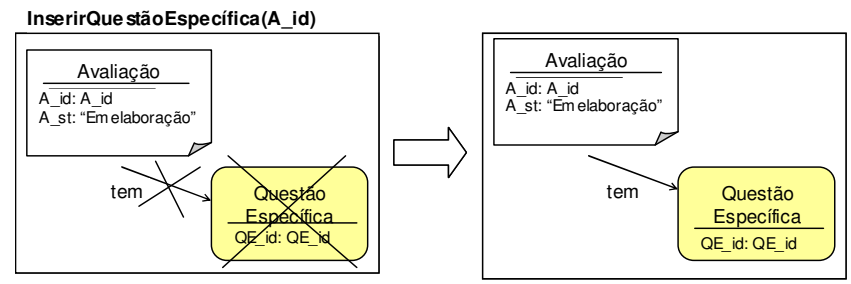

Figura 9 - Regra InserirQuestãoEspecífica

Quando estiver editando uma avaliação, o professor pode definir que para o aluno passar de uma questão Q_id1 para outra questão Q_id2 pode ocorrer uma entre três condições: acertar ou errar a questão Q_id1, ou ainda indiferente, ou seja, tanto faz errar ou acertar a questão Q_id1. A regra definida na figura 10 especifica a situação em que no momento da elaboração da avaliação não existe nenhuma conexão definida entre Q_id1 e Q_id2 e deseja-se inserir uma conexão de erro. O resultado da aplicação da regra é: se o aluno errar a questão Q_id1, a próxima questão disponível será Q_id2.

\footnotetext{
${ }^{1}$ No lado esquerdo é indicado o que deve ocorrer no grafo, mas também podem ser usadas Negative Application Conditions (NACs) que indicam o que não pode ocorrer no grafo para que a regra seja ativada. NACs são representadas por itens riscados ou ainda colocadas em separado da regra.
} 


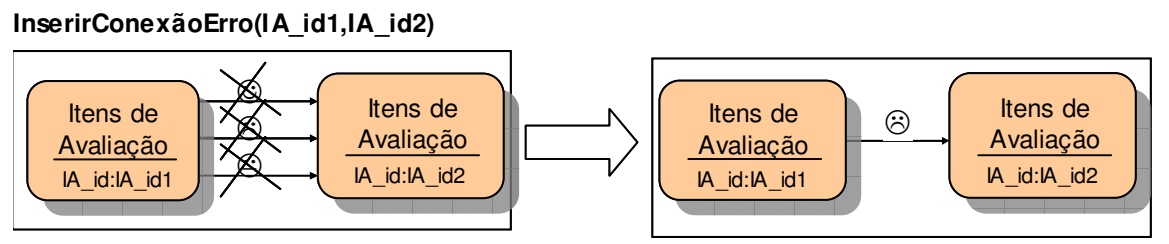

Figura 10 - Regra de inserção de conexão do tipo Erro

Dentre outras funcionalidades do AvaEditor, a aplicação da avaliação é uma função importante disponível para o professor. A regra AplicaAvaliaçãoTurma (A_id, $\left.T \_i d\right)$ permite que uma dada avaliação A_id com status "Disponível" passe para o estado "Aplicada" e seja vinculada a turma T_id. A avaliação disponível já foi definida pelo professor e validada pelo sistema, ou seja, não tem erros estruturais, e por isso, pode ser aplicada a uma turma. É importante observar que a aplicação desta regra habilitam outras regras que sincronizam a avaliação com os alunos das turmas.

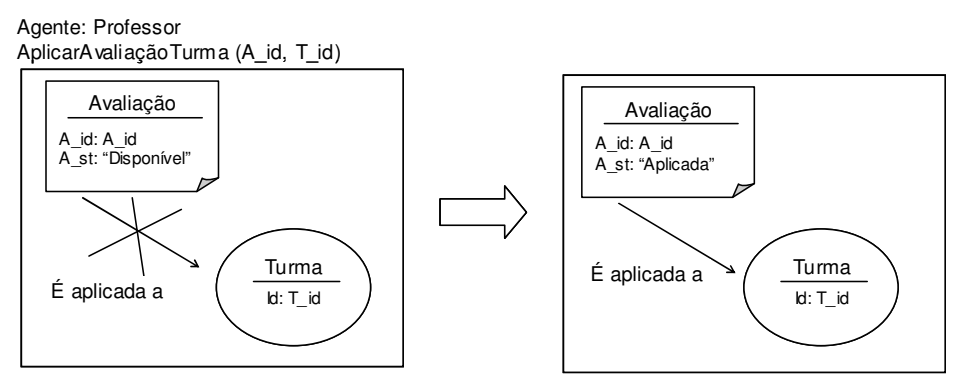

Figura 11 - Regra para aplicar avaliação em turma

\subsubsection{Semântica da Execução de Avaliações no AvaWeb}

Após a avaliação ter sido criada através de um editor visual que obedece as regras de sintaxe no AvaEditor, a sua execução (solicitada pelo aluno) depende das regras semânticas. Foram desenvolvidas diversas regras para garantir a seqüência correta definida pelo professor. A regra ApontarPrimeiraQuestão é apresentada como exemplo na figura 12. O objetivo da regra é apontar a primeira questão a ser realizada pelo aluno. Para isso é necessário que a avaliação esteja "aplicada" e que o aluno já tenha iniciado a mesma (estado "Em andamento" para a ocorrência de avaliação). Além disso, o nodo Início aponta para um item de avaliação pertencente à avaliação e não existe nenhuma questão sendo apontada para o aluno realizar. O lado direito atribui o relacionamento "questão atual" ao item de avaliação apontado. Neste momento, o aluno poderá ativar a regra "Responder questão" (não mostrada aqui).

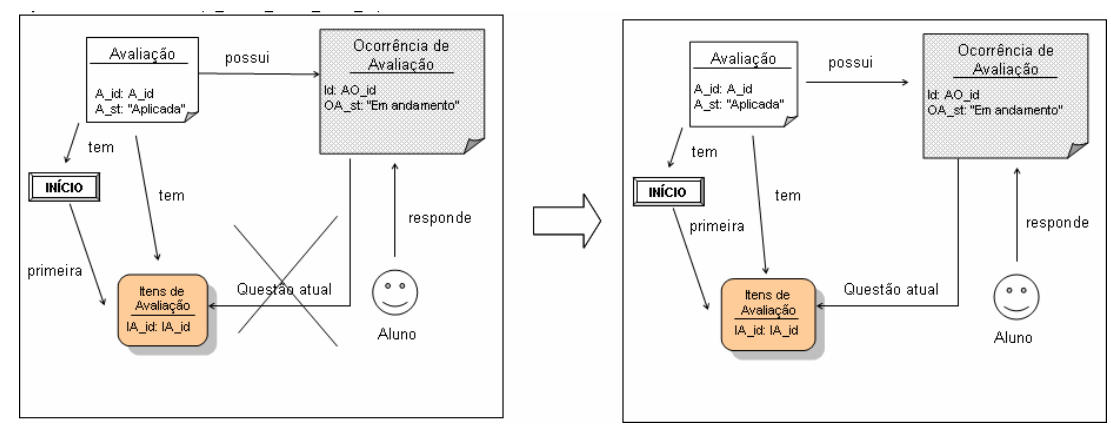

Figura 12 - Regra para definir a questão a ser respondida

\section{Trabalhos Relacionados}

A maioria dos sistemas existentes que possuem ferramentas para avaliação, tais como o usado pela UNISC (Berner, 2000), o AULANET (Noya, 2001) (Fuks et al., 2003) e o 
Teleduc (Ferreira, 2003) (Otsuka e Rocha, 2002), segue o padrão de cadastro de questões de vários tipos, permite a elaboração de avaliação, é desenvolvida para o ambiente WEB e serve de apoio tanto ao ensino presencial quanto a distância. $\mathrm{O}$ $A v a W e b$ também possui estas características, porém o grande diferencial é apresentar um modelo de avaliação que tem um editor gráfico especificado formalmente e permite a geração de avaliações diferentes por aluno, de acordo com o desempenho individual de cada um.

Dois trabalhos sobre sistemas de avaliação também tratam da personalização de avaliações. O primeiro, descrito em (Zaina, 2002), apresenta a ferramenta AvaliaOnline, que trabalha com questões de múltipla-escolha em problemas que possuem valores numéricos e fórmulas ou algoritmos relacionados a sua resolução. Além disso, pode-se definir dependência entre as questões que compõem o teste, construindo uma árvore de questões onde o professor verifica o "caminho" percorrido pelo aluno. A desvantagem desta solução é que toda a dependência de questões é feita associando os números das questões numa interface semelhante a uma tabela, além de somente permitir questões de múltipla escolha. O segundo trabalho é apresentado em (Morais, 2002) e propõe o Hyper-Automaton (hipertexto e autômato), para criação de cursos, exercícios e avaliações através de Autômatos Finitos com Saída. Cada página de exercício/conteúdo do curso corresponde a um estado ou a uma transição de um autômato. A vantagem está em permitir a criação do material hipermídia de forma independente do autômato em si, eliminado a redundância de informações. Esta independência de conteúdo é também uma das características do $A v a W e b$, porém, como não foi encontrado um editor para o Hyper-Automaton, estima-se que o professor deva conhecer o formalismo de Autômatos para elaborar suas avaliações, o que prejudica o fator interação.

\section{Considerações Finais}

A ferramenta AvaWeb com o editor gráfico de avaliação AvaEditor foram apresentados neste trabalho baseado no modelo conceitual para avaliação adaptativa de aprendizagem. Foi modelada uma Gramática de Grafos para especificar a proposta da linguagem visual de avaliação e sua semântica, obtendo com isso facilidades como ausência de ambigüidade, definição clara das restrições do sistema e facilidade de prototipação. É importante observar que a ferramenta, por ser um modelo bem especificado, pode ser facilmente estendida ou adaptada para atender novos requisitos e ainda integrada a diversos ambientes de aprendizagem.

O professor poderá melhorar sua produtividade fazendo uso de um banco de questões, pois tendo uma base de questões atualizada e aderente ao plano pedagógico que se propõe seguir, poderá sempre observar pontos de melhorias e atuar como um revisor aperfeiçoando a base de questões e disponibilizando para si e para os demais professores, um rico material de trabalho.

O uso do editor gráfico de avaliações AvaEditor traz diversos benefícios para o professor, tais como: facilidade para organizar uma avaliação tendo em mente os objetivos a serem atendidos por esta avaliação, visualmente ter uma imagem de quais possíveis avaliações podem ser geradas de acordo com o resultado de cada aluno, mudar as questões associadas às questões específicas, balancear as avaliações com relação ao quantitativo de questões e oferecer avaliações diferentes, porém com o mesmo nível de dificuldade para os alunos. Além disso, é possível a correção automática de questões objetivas e a correção de questões discursivas pelo professor. Com isso, o aluno sempre terá um retorno sobre o seu desempenho.

Como melhorias a serem implementadas no AvaWeb, pretende-se inserir facilidades para correção automática de questões discursivas e ainda aperfeiçoar sua interface com o usuário. Pretende-se também adequar o AvaWeb à metodologia de 
ensino orientada a problemas, bem como ao modelo de avaliação organizacional, pois são abordagens que necessitam de tecnologias que apóiem os seus processos.

\section{Referências Bibliográficas}

BARDOHL, R. et al. Appliccation of Graph Transformation to Visual Languages. In: Ehrig, et al. (Eds.) Handbook of Graph Grammars and Computing by Graph Transformation. Volume 2. World Scientific, Singapore, 1999.

BERNER, V. Estudo sobre Mecanismos de Avaliação de Aprendizagem em Ensino a Distância. Santa Cruz do Sul: UNISC, 2000.Trabalho de Conclusão de Curso.

CERNY, R.Z. Uma reflexão sobre a avaliação formativa na educação a distância. Revista Brasileira de Educação, Santa Catarina, 2001. Disponível em: <http://www.anped.org.br/24/tp1.htm> Acesso em: 15 fev. 2006.

FERREIRA, T. Gerenciador de Avaliações: Uma Ferramenta de Auxílio à Avaliação Formativa para o Ambiente de Educação a Distância TelEduc. Campinas: Unicamp, 2003. Dissertação de Mestrado.

FUKS H.; CUNHA, M. L., GEROSA, M. A.; LUCENA, C. J. P. : Participação e Avaliação no Ambiente Virtual AulaNet da PUC-Rio, In: SILVA, M.; Educação Online: Teorias, Práticas, Legislação e Formação Corporativa. Rio de Janeiro: Edições Loyola, 2003. p. 231-254. Disponível em: <http://www.les.inf.pucrio.br/groupware>. Acesso em: 01 nov. 2005.

MORAIS, C. T. Q. Hyper-Automaton: Avaliação Interativa de Alunos em Cursos na WEB Baseado em Autômatos Finitos. Porto Alegre: Universidade Federal do Rio Grande do Sul, 2002. Dissertação de Mestrado.

MURAN, J.M. Novas tecnologias e mediação pedagógica:Ensino e aprendizagem inovadores com tecnologias audiovisuais e telemáticas. Campinas: Papirus, 2003. p.30-32.

NOYA, R. Quest - Um Sistema de Avaliação Educacional para a Web. Rio de Janeiro: PUC, 2001. Dissertação de Mestrado.

OTSUKA, J. L.; ROCHA, H. V. A caminho de um modelo de apoio à avaliação contínua. In: Workshop de Informática na Escola, 8., 2002, Anais. Florianópolis: Sociedade Brasileira de Computação/Universidade Federal de Santa Catarina, 2002. (CD-ROM).

REIS, C. A. L. Uma Abordagem Flexível para Execução de Processos de Software Evolutivos. Porto Alegre: PPGC/UFRGS, 2003. Tese de Doutorado.

RIBEIRO, L. Métodos Formais de Especificação: Gramáticas de Grafos. In: Escola de Informática da SBC - Sul, 2000, Anais. Santa Maria: Sociedade Brasileira de Computação/Universidade Federal de Santa Maria, 2000.

ZAINA, L. A M. Acompanhamento do aprendizado do aluno em cursos a distância através da WEB: metodologias e ferramenta. São Paulo: Escola Politécnica da Universidade de São Paulo, 2002. Dissertação de Mestrado. 